\title{
Research on the Construction of Stadium Resource Sharing Service Platform under the "Internet +" Background
}

\author{
Cao Yang \\ Department of Physical Education, Qiqihar Medical College, Qiqihar, Heilongjiang, 161000, China
}

Keywords: Internet +, Resource Sharing, Service Platform, Sports Industry

\begin{abstract}
In the context of Internet + , the effective use of resource sharing service platforms provides a good communication space for sports enthusiasts, which can not only improve the utilization efficiency and quality of stadiums, but also further promote the health of the sports and training market. Development to achieve the optimal transformation of China's sports industry. In the context of Internet + in this paper, the construction of the stadium resource sharing service platform is discussed in detail.
\end{abstract}

\section{Basic Concepts of Social Resources for Sports Resources}

The stadium is the basis of the scene for the development of sports activities, as well as the material basis. This is one of the indicators of the degree of social civilization. In addition to serving a school or an event, it will also become a window for the modern city. It is a cultural exchange and sports development Pillars. Many countries have developed the content of this stadium with the goal of becoming a "healthy country". At present, the open internationally recognized model of stadiums and gymnasiums in China is aimed at driving public fitness and providing convenient fitness guidance for many citizens, so as to promote national fitness and the sharing of sports resources can go to the normal operating track.

The so-called sharing, for the enterprise, sharing refers to the use of certain means to achieve complementary resources. The sharing of school education resources is an inevitable way to achieve lifelong education. It will not only help promote the development of education in a more equitable direction, but also effectively promote the establishment of a good relationship between the two and improve the relationship between schools and the community. The school's material resources can be effectively shared with society, but it should be applied in a more professional direction, and a balance must be made between time effectiveness and fair morality [1]. The sports resource sharing service studied in this article refers to opening to the outside world free of charge or for a fee on the premise of ensuring venue training and competition activities. When opening to the outside world, certain service methods are also required to improve the quality of venue use. And utilization.

\section{The Necessity of Resource Sharing in Stadiums}

As the basis for sports activities, stadiums have an important role in promoting national fitness. In the future, stadiums should not only be used for competitive games, but also popularized with the general public, which provides a good platform for sports and leisure. Because many stadiums are too outdated and singular in the management mode at present, the utilization rate of stadium resources is very low. Therefore, it is the future stadiums to realize internal adjustments, optimize their service models, and maximize the use of resources. The inevitable direction of development [2]. Using the content of the Internet to establish a good sharing platform is also an inevitable part of stadiums to be upgraded in the future. Only by actively connecting with the times can sustainable development be better achieved.

\subsection{Low Utilization of Stadiums}

With the promotion of the concept of comprehensive fitness in the society, the improvement of public sports services has made more and more various gym resources. At present, there are about 2 
million stadiums in China, of which the area of stadiums per capita can reach 1.57 square meters. The increasing number of stadiums and gymnasiums provides a good platform for national fitness. However, the current low utilization rate of stadiums and gymnasiums is still a problem that needs to be solved urgently. At present, many large stadiums are funded by the government. The purpose of construction is to meet the development of urban sports. It will meet a variety of contents, such as craftsmanship and competitions. However, supporting services and post-match operation issues have not been carefully considered. Therefore, it is necessary for the person in charge of the public gymnasium to change their concepts and update the operating model in a timely manner so that more stadiums can operate effectively, so as to encourage people to participate in the national fitness and improve the openness and utilization rate of the stadiums. Let the stadiums get further sharing.

\subsection{The Current Operating Model is Relatively Single}

Regardless of whether it is a school or a stadium in the society, the operation model is very single, mostly based on the public institution model, and only a small part is operated by the company. The operating mode of public institutions mainly relies on the subordinate public institutions of the Sports Bureau for related logistic management. This mode usually does not allow employees to have too much initiative and creativity, and there is no certain incentive mechanism. The gymnasium is still in an exploratory stage, which requires creative personnel to mobilize the development of the gymnasium, so as to promote the resource sharing and sustainable development of the gymnasium and realize the resume of the network communication platform. The innovation of the operation model can not only make the stadium active, but also lay a good foundation for national fitness. The management department should fully start from the construction of the stadium and the operation of the event, explore a complete system, promote the upgrade and transformation of the stadium, broaden the development channels for the stadium, and enrich the new operation mode of the stadium [3].

\subsection{Contradiction between Supply and Demand of Stadiums}

The need for stadiums is a public need. With the continuous improvement of people's material living standards, more and more people will devote offline time to exercise. The increase in the number of sports population will lead to an increase in market demand. When there is no effective balance between supply and demand, Then there will be some contradictions. People's demand for stadiums is constantly increasing. This is because the public has a close need for physical exercise. At the same time, this is also related to the degree of openness of stadiums. Therefore, it is necessary for stadiums to rationalize their opening hours to make the regional resource distribution and structure more reasonable. The existence of stadiums must truly bring benefits to the surrounding public, so as to improve the efficient allocation of sports resources. To promote the high-quality development of sports resources.

\subsection{Lack of Professional Docking Platform}

People's demands for physical exercise are diverse, and the diverse demands have brought opportunities and challenges to the development of the stadium. For example, in the context of the Internet, although social software is increasing, there are very few platforms that can really bring professional gym resource suggestions or service exchanges to consumers. Because many sports communication platforms lack a systematic summary, they cannot fully meet the needs of the public for fitness, and will restrict the development of national fitness to a certain extent. Therefore, it is necessary to establish a shared resource network service platform for communities, stadiums, and schools, make full use of the big data platform, and build a comprehensive and multifunctional gym service platform to improve the intelligent management of gym resources and promote the efficiency of gym Utilization and green development. 


\section{Advantages of Building a Resource Sharing Service Platform}

\subsection{Can Further Promote the Development of National Fitness}

The resume of the stadium resource sharing platform can solve the conflict between supply and demand between the stadium and the audience with a modern service method, so that the majority of sports enthusiasts can have a platform for equal communication and choice. The public can also learn about some sports events in a timely manner through the platform's shared services. The venues can use the information to coordinate according to their preferences and time, and then devote themselves to the projects they love. The resource sharing of sports stadiums should use GPS positioning system to reasonably plan the route for users, so that people can know the information of the surrounding stadiums without leaving home, and the masses can choose to exercise nearby. It can effectively save time without losing the motivation for sports because of finding a usable venue. With the continuous increase of sports groups, people's use of shared resource platforms will become higher and higher, and the demand for their functions will also increase. Therefore, the sharing platform also needs to continuously improve its own content, in order to more Promote the development of mass sports.

\subsection{Improve Venue Resource Utilization}

The resource utilization rate of the stadium is an important indicator of the stadium's operating capacity. In the context of the Internet, the service platform can not only provide demand information to the public through intelligent data processors, but also reflect some of the audience's preference information and problems to Suppliers, such two-way communication on the service platform can not only bring convenience to the public, but also avoid problems during the peak period, and further improve the venue's resource utilization. The utilization of venue resources requires the venue operator to develop in the direction of more functions in planning. Different areas can be targeted for optimization according to the needs of the group. As the operation time accumulates, the operation of the venue will be upgraded to an original level, and it will also be able to reflect a stronger comprehensive quality, which can not only meet the fitness needs of contemporary people, but also effectively improve the sports events. The contractor's ability to further improve the utilization rate and service quality of the venues on the basis of promoting national fitness.

\subsection{Promote the Training of Reserve Talents}

In past sports training, the management of sports training institutions did not belong to the education department or the sports department. Because the current sports training market is becoming more and more popular, and more and more people choose this service, but many people lack the corresponding awareness of rights protection, which has led to some sports training institutions will be confused, and the problems in this industry will also increase. More and more: For example, the qualifications of the coaches, the training standards of the first-level venues, etc., these are not supervised by the relevant agencies. Once there is a problem, the accountability is a problem everywhere. Therefore, the service platform can incorporate the content of supervision. For some issues in sports training and venue operations, users can provide feedback in a timely manner to achieve upload and release, and promote the development of sports training in a more standardized and intelligent direction. . Judging from the current situation of youth training, physical training can indeed expand the scope of talent training and further promote the further development of China's sports industry. If sports stadiums can assist this on the service platform, it will be a great opportunity for social development. Good things.

\subsection{Promote the Transformation of the Sports Industry}

The upgrading and optimization of the sports industry structure is a huge and systematic content. It needs to connect the economic relations, quantitative proportions, etc. between the various production sectors in order to reflect the interdependence and constraints between sports products 
and service sectors. At the same time, it can also reflect the situation of the preparation of various departments of sports resources and the distribution of the sports industry. Stadium resources should strive to be upstream in the general environment, while complying with the optimization trend of the sports industry structure, in a timely manner, the problems existing in the current transformation should be discovered in order to better optimize the relationship between various elements of the sports industry, promote the masses, The optimized development of the market and public service system has laid a good and rich foundation for the future transformation of the sports industry.

\section{Construction Direction of Stadium Resource Sharing Service Platform under "Internet +" Background}

\subsection{Optimizing GPS Positioning System}

With the continuous progress of science and technology and the continuous popularization of global positioning software, it has been widely used in all walks of life and gradually penetrates into people's lives. In addition, people's demand for GPS positioning is also increasing. The stronger. Unlike traditional APP software, GPS positioning can make the service and operation of stadiums more convenient and efficient. With the help of GPS positioning system, sports enthusiasts can easily browse the information of nearby venues at home, and in any city Can make reservations for venues. Incorporating a GPS positioning system into the shared service platform can provide users with the nearest travel solution, allowing more sports enthusiasts to experience the convenience brought by the intelligent service platform.

\subsection{Optimize Personal Information System}

Setting up an optimization system for personal information is mainly for the purpose of more targeted services. At present, the demand for stadium resources has blurred the concepts of individuals, families, and units. There are more and more groups participating in the masses, and the methods of participation have become more diverse. Although this is a good thing for national fitness, for the management of the platform, it will increase a certain work cost and achieve standardized management, which requires the personal information system to fully play its role. In the personal information system, the main purpose is to enter and identify personal information, and some groups can be stored in the service device by entering personal information or scanning facial information, so that they can be automatically identified at a later stage. The setting of the personal information system can effectively save the time for sports enthusiasts to choose and enter the stadium. It can also further promote the funny use of stadium resources, effectively alleviate the embarrassing periods of late peaks and weekends, and further reduce the staff's work. This pressure laid a good foundation for the future intelligent development of the venue.

\subsection{Optimize the Resource Control System}

The so-called resource control system is to establish a reliable database for the interior of the venue through the analysis, collation and verification of big data. Use this as a support to provide users with information storage management, security management and other content, so that users can see the flow of venue information through this platform, and can also find related sports information through the platform to meet their own exercise needs . The resource control system not only needs to store the information of the venue, but also needs to have close links with the outside to maximize the sharing of resources. Of course, in this process, it is necessary to strictly control the relevant data and information, unify the charging standards, and avoid vicious market competition, which will bring users a more intelligent and green venue experience.

\section{Conclusion}

After the concept of Internet + was put forward, all walks of life also have new directions in reform and innovation, and at the same time will face various challenges. Through the exploration of the Internet + model, understand the significance of the stadium resource sharing platform, and 
provide timely and effective information feedback to the masses, so as to improve the utilization rate and use quality of stadiums, which will give China's sports industry a qualitative Fly over. Therefore, in order to better fit the theme of national fitness and national sports, we should promote and continue to practice the content sharing of stadiums and resources.

\section{Acknowledgements}

Soft Science Project of Qiqihar Science and Technology Bureau, Project name: Research on the Interactive Development of Qiqihar Ice and Snow Industry and Universities (Project Number: RKX-201707).

\section{References}

[1] Xu Huai, Gu Jian, Wang Yong. Optimization and Sharing of Sports Resources of College Stadiums in Changzhou Science and Education City Vocational Colleges. Sports World (Academic Edition), no. 11, pp. 31-32, 2019.

[2] Yang Chunguang. On the social sharing of physical education resources in colleges and universities from the perspective of the sharing economy. CPC Shenyang Municipal Committee, Shenyang Municipal People's Government, International Academy of Production Engineering, Chinese Mechanical Engineering Society. Thesis of the 16th Annual Scientific Academic Conference of Shenyang Collection (Economic and Social Sciences). CPC Shenyang Municipal Committee, Shenyang Municipal People's Government, International Production Engineering Academy, Chinese Mechanical Engineering Society: Shenyang Science and Technology Association, pp. 83-88, 2019.

[3] Lei Xiuping. Research on the Operating Mechanism of University Stadium Facilities Resource Sharing. Contemporary Sports Science and Technology, vol. 9, no. 28, pp. 227-228, 2019. 